\title{
Construyendo una Geografía Crítica y Transformadora. En defensa de la Ciencia y la Universidad Pública
}

\author{
Bernardo Mançano Fernandes \\ mancano.fernandes@unesp.br \\ São Paulo State University - Universidade Estadual \\ Paulista, UNESCO Chair in Territorial Development \\ and Education for the Countryside, Brasil
}

\author{
María Laura Silveira \\ maria.laura.silveira.1@gmail.com \\ CONICET, Instituto de Geografía, Universidad de \\ Buenos Aires, Argentina
}

Palabras clave: Geografía, Territorio, Mundo Tecnificado.

Keywords: Geography, Territory, Technical world.

Cita sugerida: Fernandes, B. M. y Silveira, M. L.

(2021). Construyendo una Geografía Crítica y Transformadora. En defensa de la Ciencia y la Universidad Pública. Geograficando, 17(1), e096. https://doi.org/10.24215/2346898Xe096

En el marco del VII Congreso Nacional de Geografía de Universidades Públicas y XXI Jornadas de Investigación y Enseñanza en Geografía, realizado el 9, 10 y 11 de octubre de 2019 en la Ciudad de La Plata, Buenos Aires, el Dr. Bernardo Mançano Fernandes y la Dra. María Laura Silveira fueron los encargados de las conferencias inicial y final del mencionado congreso.

La presentación estuvo a cargo en el primer caso por la Prof. Daniela Patricia Nieto y en el segundo caso por el Prof. Héctor Luis Adriani.

La disertación del Dr. Bernardo Mançano Fernandes se tituló: “Los territorios como ellos son...”. y la de Dra. María Laura Silveira: "La Geografía ante los presagios de un mundo tecnificado".

Los invitamos a revivir las conferencias en:

Link:

https://www.youtube.com/watch?v=gqTWbfB0pZg

https://www.youtube.com/watch?v=gqyYPBZ_tBk 
El evento fue organizado por el Departamento de Geografía y el Centro de Investigaciones Geográficas de la Facultad de Humanidades y Ciencias de la Educación UNLP, y por la Red de Geografía de las Universidades Públicas de la República Argentina. 